\title{
Epidemiology of companions of the patients in family medicine: Making the invisible visible
}

\author{
José Luis Turabian ${ }^{1 *}$, Raul Cucho-Jove ${ }^{1}$, Luis Enoc Minier-Rodriguez ${ }^{1}$, Francis Eliant Rodriguez-Almonte ${ }^{1}$, Sandra Moreno-Ruiz ${ }^{1}$ and \\ Alejandro Villarin-Castro ${ }^{2}$ \\ ${ }^{1}$ Specialist in Family Medicine and Community, Health Center Santa Maria de Benquerencia, Toledo, Spain \\ ${ }^{2}$ Teaching Unit of Primary Care and Community, Primary Care Management, Toledo, Spain
}

\begin{abstract}
Objective: Describe the frequency of companion with the patient, and the characteristics of both, in Family Medicine consultations.

Methodology: Observational, descriptive and prospective study in a Family Medicine office in Toledo, Spain. For each patient and companion, the following variables were collected, among others: age, gender, chronic illness, chief complaint, medications taken, social class, request for additional tests, kinship, social status and availability of companion. Descriptive data, which were expressed by standard measures of central tendency and dispersion were obtained.

Results: A sample of 445 patients was obtained. The frequency of the presence of a companion was $23.8 \%$. In the companions, the age group between $40-64$ years with $60 \%$ [95\% CI 50.17 to 69.99 ] was the predominant. Kinship of companions was mainly wife in $43 \%$. The availability status of companions was: worker in the $37 \%$, housewife $27 \%$, and retired $23 \%$. The $45 \%$ of companions were classified as collaborators. In patients predominated: the age group $\geq 65$ years: $39 \%$ [95\% CI 29.67 to 49.05 ], the $59 \%$ [ $95 \%$ CI 49.46 to 68.86 ] were women, with an average of 2 chronic diseases, and taking an average of 3 drugs, and with derivations hospital specialist in $18 \%$ of patients [ $95 \%$ CI 11.15 to 26.56 ].

Conclusions: There is a moderately high prevalence of the presence of a companion, who is in almost one of every 4 visits served in Family Medicine. The accompanying "type" is a middle-aged adult, predominantly the couple, worker, housewife or retired. Accompanying patients are older women, with polypharmacy, and that generate hospital referrals. The companion of the patient is an area of Family Medicine which has received little attention, and his presence may go unnoticed, but his frequency deserves the attention of the physician, who must deepen his characteristics and meanings, "making the invisible visible" in the care of these patients with companions.
\end{abstract}

\section{Introduction}

An important feature of Family Medicine is taken into account the companions in attendance of individual patients. The physician-patient relationship is part of the patient's larger social system and is influenced by the patient's family. The context of the patient includes family, friends, work, religion, school, and health resources. Recognition of this context allows the doctor does not see health problems as isolated events but as a response to, or inserted in, life crises, stress, inadequate habits, or family dysfunction [1,2].

Many consultations occur on a patient only, but other times involve companions with patients in the medical office. A patient's family member can be a valuable source of health information and can collaborate in making an accurate diagnosis and planning a treatment strategy during the visit to the office [3]. A second adult-usually parents or husband or wife accompanying the patient consultation is always significant and deserves the attention of the doctor [4].

Conventionally, physician focuses on an encounter between two people: the patient and the physician. In practice, a third person (a companion) frequently accompanies a patient during a medical encounter [5,6], and these companions are usually family members [7]. Thus, it is necessary to institute a mode of practice family oriented, where clinician-family relationships are critical elements to improve quality of care [8].

The medical attention taking into account the "companion" of the patient is a particular case of the care focused on the "context" of the patient. The family doctor, to treat patients, goes from context to body (not the other way around: from the body to context). The family doctor makes a "care centered on the context of the patient". In the consultation of Family Medicine, first, the doctor should put attention to the context of the patient: his or her "companions" -family, community...-, before treating patient complaint [9]. Therefore, it is important that when our patient goes into to consultation, the family doctor loses a few seconds to observe the companion. This could give much information $[1,10]$.

The major results of existing studies suggest that the regular presences of companions of the patients in consultations are often perceived as helpful. Accompaniment to medical visits is associated with better self-care maintenance and management, and this effect may be mediated through satisfaction with provider communication [11]. Also companions provide company, emotional support; and they have

Correspondence to: José Luis Turabian, Teaching Unit of Primary Care and Community, Primary Care Management, Toledo, Spain, E-mail: jturabianf@hotmail.com

Key words: companions, family practice, family members, caregivers, visit to doctor's office, physician-patient relations

Received: August 17, 2016; Accepted: October 03, 2016; Published: October 06,2016 
a role in mobility and decision making of the patients [12]. However, their participation often poses challenges. Doctors may differ about the most useful behaviors of companions (e.g., information or support) and can have problems (for example the companion dominant or with demanding behavior).

Despite all the above, the reports, reviews or investigations about the presence of a companion of the patient in consultation, are rather scarce in our environment. Very little research has examined the influence of people who accompany patients on everyday visits to the doctor $[13,14]$, and previous research on the communication in medical encounters has primarily focused on dyadic interactions between physician and patient [15].

In this context, we present a study whose objectives were:

1.-To describe the frequency of the presence of the companion of the patient in Family Medicine consultation.

2.- To describe the characteristics the patient and his companion in Family Medicine consultation, according age, sex, disease, drugs, and others variables.

3. Qualify the companion of the patient according to his attitude.

\section{Material and method}

Observational, descriptive, prospective study, which included patients of both sexes over 14 years of a Family Medicine office which has a quota of 2,000 patients. We calculated the sample size for an estimated rate of companion of $30 \%$, for a population of consultation of 2000 persons, a confidence limit of $5 \%$, and a confidence interval of $95 \%$, in 278 patients [16].

From randomly chosen day for 15 consecutive days, from 26 November 2015 to 18 December 2015, the visited patients were included, and data from the companions with patients were collected. Companion was defined as any person who accompanied the patient in the consulting room or that consulted instead the patient. Patients were included only one time. Thus, were excluded the repeated consultations of same patient, including only the first visit. If the patient had two companions only was included the data from the first of them in analysis.

For each patient and companion the following variables were collected: age, sex, chronic disease (defined as "any alteration or deviation from normal that have one or more of the following characteristics: is permanent, leaves residual impairment, is caused by a non-reversible pathological alteration, it requires special training of the patient for rehabilitation, and/or can be expected to require a long period of control, observation or treatment") [17], and classified according to International Classification of Diseases (ICD-10) [18],

Table 1. Examples of different types of companions according to physician. taking medication, collecting the therapeutic drugs group, classified according to ATC code or system Anatomic Classification, Therapeutic, Chemical [19], sick leave of the patient, the problems in the family context (based on the genogram, and valued by the family doctor who performed the genogram at the past time, by viewing the family scheme (the genogram was a schematic model of the structure and processes of a family, included the family structure, life cycle when that family is, the important life events, family resources, and family relational patterns) [20-23], social-occupancy class, according to the Registrar General's classification of occupations and social status code [24,25], type of companion classified as "Collaborator", "Passive", "Intrusive", "Guilty", "Sick", and "Critical / Angered" according to the definition given in Table $1[1,26,27]$ from the decision of the usual doctor in the medical office, and who remains in the same consultation for over 25 years, if the analytical or imaging test was requested for the patient, if the patient needs a consultation with the specialist, the companion relationship with the patient, and the social availability of companion in relation to the patient.

A Microsoft Excel ${ }^{\otimes}$ file was built, and the the IBM SPSS Statistics for Windows, Version 18.0. Armonk, NY: IBM Corp software was used [28]. Descriptive data, which were expressed by standard measures of central tendency and dispersion, were obtained. The informed consent of all patients or their guardians for using of data in research was obtained.

\section{Results}

During the 15 days of data collection, a sample of 445 patients was obtained, of whom 106 were patients with a companion $(24 \%$ frequency or prevalence of the presence of the companion) (Figure 1). In $63 \%$ of consultations with companion (95\% CI 53.28 to 72.36 ) the patient was present. With the 106 patients were 104 companions (there were patients who shared companion).

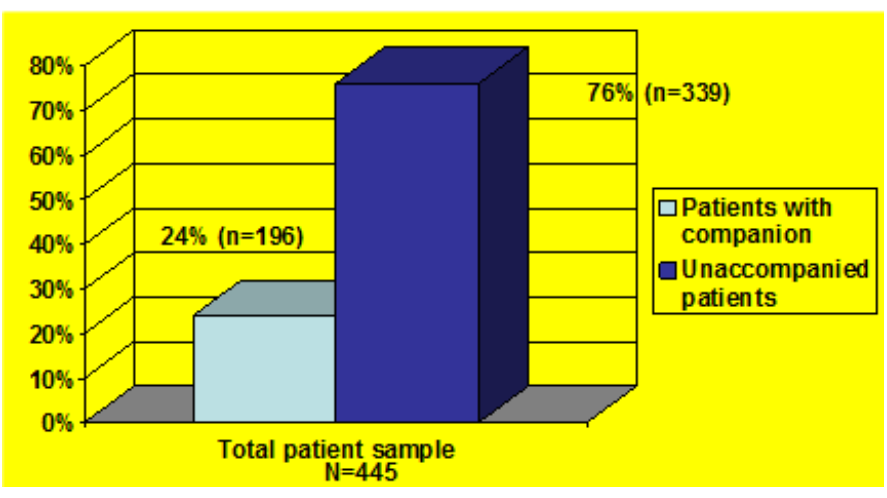

Table 1. Examples of different types of companions according to physician.

\begin{tabular}{|l|l|}
\hline Definitions of the Type of Companion & Definition \\
\hline "Collaborator" & $\begin{array}{l}\text { Helps the doctor spontaneously and with respect, gives relevant information about the patient and adopts a position of responsibility in the } \\
\text { therapeutic process. Notes the doctor's instructions. He or she asks questions. Explains the doctor's instructions to the patient }\end{array}$ \\
\hline "Passive" & $\begin{array}{l}\text { He or she generally it remains in the waiting room, is not involved or does poorly in the development of clinical interview } \\
\text { in the patient. He or she Interrupted the doctor-patient relationship }\end{array}$ \\
\hline "Intrusive" & $\begin{array}{l}\text { He or she feels guilty about their inability to provide a certain level of care that are necessary for the patient, but that would require major } \\
\text { changes in lifestyle of companion }\end{array}$ \\
\hline "Guilty" & $\begin{array}{l}\text { He or she projects his symptoms on the patient. The companion is actually the real sick, and reflects their anxieties and demands on the } \\
\text { patient }\end{array}$ \\
\hline "Sick" & He or she ago criticism of a thing, especially for improvement. He or she can show anger, disgust or anger \\
\hline "Critical / Angered" & \\
\hline
\end{tabular}




\section{Results in the companions}

Regarding the 106 companions (with an average of 1.02 companions per patient), their mean age was $52 \pm 14$ ( $<40$ years: $20 \%$ ( $95 \%$ CI 12.53 to 28.91 ), $40-64$ years: $60 \%$ (95\% CI 50.17 to 69.99 ) and $\geq 65$ years. $20 \%$ (95\% CI 12.53 to 28.91 ) they were women: $62 \%$ (95\% CI 52.46 to $71.80)$.

There were 2 companions with one patient in the $2 \%$ of patients $(95 \%$ CI 0.22 to 6.65). Kinship of the companion was predominantly wife in $43 \%$, the child / girl in $27 \%$, and the mother in $17 \%$. Companions have a total of $2 \pm 2$ chronic diseases. Musculoskeletal system and connective tissue diseases in $30 \%$ of companions, mental and behavioral disorders in $29 \%$ of the companions, and circulatory system diseases in $26 \%$, were predominant. The companions took an average of $2 \pm 2$ medications. Medications taken predominantly were of cardiovascular system with $22 \%$, nervous system with $20 \%$, and system skeletal muscle $18 \%$. The problems in familiar context of companion were found in $47 \%$ (95\% CI 37.18 to 57.81 ). The social class-occupancy prevalent in the companion was unskilled workers in $58 \%$. The situation of social availability of companion was predominantly worker in $37 \%$, housewife $27 \%$, and retired at $23 \%$. Companions were classified as "collaborators" in the $45.2 \%$ (Table 2).

\section{Results in the patients with companions}

Regarding patients with companion (or absent patient represented by the companion), the mean age was $54 \pm 23$ years; by age group $<40$ years: $30 \%$ (95\% CI 21.02 to 39.28 ); $40-64$ years: $31 \%$ (95\% CI 22.71 to 41.21 ); $\geq 65$ years: $39 \%$ (95\% CI 29.67 to 49.05 ). The $59 \%$ (95\% CI 49.46 to 68.86 ) were women, with an average of chronic diseases $2 \pm 1$.

The predominant diseases were of the circulatory system in $41 \%$ of patients, endocrine, nutritional and metabolic diseases in $31 \%$, mental and behavioral $31 \%$ disorders, diseases of the musculoskeletal system and connective tissue in $28 \%$, and respiratory system diseases in $19 \%$. Patients were taking an average of $2.96 \pm 3.03$ drugs. The predominant group was nervous system drugs, in $41 \%$ of patients, the cardiovascular system in $35 \%$, and the digestive system and metabolism $30 \%$. The $12 \%$ (95\% CI 6.69 to 55.26 ) of patients were off work. In 45\% (95\% CI 35.22 to 55.26) of the patients was considered that there were problems in the family context. The $57 \%$ were unskilled workers, $17 \%$ semi-skilled, $13 \%$ students. They consulted predominantly by diseases of the circulatory system in $19 \%$; by diseases of the respiratory system in $14 \%$; and by musculoskeletal disorders and connective tissue in $14 \%$. An analytic test was ordered in $4 \%$ (95\% CI 1.03 to 9.38 ) of patients, and an imaging test in $1 \%$ ( $95 \%$ CI 0.02 to 5.14). There were specialist hospital referrals in $18 \%$ of patients ( $95 \%$ CI 11.15 to 26.56 ) (Table 3).

\section{Discussion}

The presence of family members in the office visit creates opportunities for the family doctor: it allows speak with the patient and family on their family history and context, and this knowledge can be important for decision-making and implementation of therapeutic measures. The positive consequences of the presence of companions would be: he or she can give information on the severity of the disease, prevents anxiety, builds trust, promotes obtaining more information on the health situation and disease patient, it favours family dialogue, aids to decision-making, improves satisfaction, provides support, and improves patient health outcomes. Consequently, it is recognized that to improve attendance and potential outcomes of the patient, the doctor should focus on a whole range of approaches to facilitate the participation of companions-caregivers in clinical encounters [1].

\section{Prevalence of the companion of the patient in consultation}

It has been reported that visits in which one or more family members are present, are quite common, and their prevalence figures or frequency are ranging from $16 \%, 30 \%, 35 \%, 39 \%, 53 \%$, and up to $62 \%[5,7,8,13,29-31]$. We found that $23.86 \%$ of the interviews were with companions, the same figure as Castillo-Barrera (27), also in Spain.

\section{Features of the companions}

The companions of the patients are usually family members, and this relationship is present in $93 \%$ of cases [5], being a woman in $73 \%[13,30]$, aged between $21-40$ years [13], and she is the wife in $48 \%$ [29,31]. Our study reproduces these data, being the companion predominant a middle-aged adult, usually the couple and housewife. We also found that their social availability to be the companion of the patient was predominantly worker in $37 \%$, housewife $27 \%$, and retired $23 \%$.

On the other hand, doctors may differ about the most useful behaviors of companions (e.g., information support) and less useful (for example, dominant companions or demanding behavior), so that preferences for participation of companions can vary greatly between different doctors. We found companions "collaborators" in the $45 \%$. These data are consistent with previously published [7,29]. It has been reported that the most frequent companion is a collaborator $(67 \%)$, followed of liabilities-silent observer (29-69\%) and intrusive (5\%) $[13,27,30]$. The problems in familiar context of companion were found in $47 \%$ (95\% CI 37.18 to 57.81 ). Our research group has communicated that the presence of companion of the patient in consultation Family Medicine is associated with familiar problems vs. the presence of unaccompanied patient [32].

The companion assumes the value as intermediary and caregiver. The care of patients "very fragile", the increasing dependence on their families of elderly patients and / or significant chronic problems, along with the complexity of health services, contributing to the perception that informal caregivers and companions have a role indispensable as "intermediaries between the health system and patient." Therefore, it is desirable to emphasize the need to discuss further about the fragility of patients with their family companions, who can be supported and trained to participate in decision-making on tasks for the care of the sick, so that they meet the needs of the patient, the doctor and family [1].

The presence of family members at an office visit creates unique opportunities and challenges for the physician while interviewing the patient. The physician must address issues of confidentiality, privacy, and agency. Special skills are required to respectfully and efficiently involve family members, while keeping the patient at the center of the visit. These skills include building rapport with each participant by identifying his individual issues and perspectives, and encouraging participation by listening to and addressing the concerns of all persons. Physicians should also avoid triangulation, maintain confidentiality, and verify agreement with the plan [33].

\section{Patient characteristics}

Patients with greater needs are most often come accompanied, which is positive. Those more likely to have a family member present include patients with a low level of health literacy, patients with chronic diseases, older patients, and women [3,7]. We find similar characteristics: the patients with companion were older women, unskilled, with polypharmacy, and generate hospital referrals. 


\section{Limitations of our study and possible future research}

Some of the limitations are: 1 ) the dynamics of the interview was not studied; 2) it was not collected the meaning or reason to be present companion; 3) the reasons for to be accompanied to the consultation were not collected; and 4) The patients' perceptions were not collected. Future studies could include these topics $[1,3,5,13,34]$.

\section{Summary and conclusion}

Our study coincides with previous research. There is a high prevalence of the presence of companion, which is present in almost one of every 4 visits served in Family Medicine. The accompanying "type" is a middle-aged adult, predominantly the couple, worker, housewife or retired, with family problems. Accompanying patients are older women, with polypharmacy, and generate hospital referrals.

The companion seems to play a secondary role, but he can be the main actor. This high prevalence of companion should remind us "make the invisible visible" and take into account the companion during assistance in individual patients [35]. Doctors should be interested increasingly in them. A second adult -usually the husband or wife or parents- accompanying the patient in consultation, or instead of him or her, is always significant and deserves the attention of the doctor. The family members are the most frequent companions of the patient consultation, and thus, it forces to a practice orientated to the family. Table 4 shows key recommendations for practice [3].

The presence of family members in the office visit creates opportunities for the family doctor: it allows talk to the patient and family about their family history and context, and this knowledge can be important for decision-making and implementation of therapeutic measures. Finally, the fact of the high prevalence of companions, leads to consider the ethical aspects of the companions in the consultation, mainly confidentiality and autonomy.

\section{References}

1. Turabian JL, Perez-Franco B (2015) Modelos de atención centrada en el "acompañante" del paciente. La familia y el contexto: en el borde de la relación médico-paciente en medicina de familia. Berlin: Editorial Académica Española. Schaltungsdienst Lange o.H.G.

2. Stewart M, Brown JB, Weston WW, McWhinney IR, McWilliam CL, et al. (1995) Patient-centered medicine. Transforming the clinical method. London: SAGE Publications.

3. Omole FS, Sow CM, Fresh E, Babalola D, Strothers H 3rd (2011) Interacting with patients' family members during the office visit. Am Fam Physician 84: 780-784. [Crossref]

4. Turabián JL, Pérez Franco B (2015) [The presence of a companion in the primary care consultation]. Semergen 41: 206-213. [Crossref]

5. Schilling LM, Scatena L, Steiner JF, Albertson GA, Lin CT, et al. (2002) The third person in the room: frequency, role, and influence of companions during primary care medical encounters. J Fam Pract 51: 685-690. [Crossref]

6. Ricci R The accompanied patient (2011) Evidencia Actualización en la Práctica Ambulatoria 14: 2 .

7. Wolff JL, Roter DL (2011) Family presence in routine medical visits: a meta-analytical review. Soc Sci Med 72: 823-831. [Crossref]

8. Main DS, Holcomb S, Dickinson P, Crabtree BF (2001) The effect of families on the process of outpatient visits in family practice. J Fam Pract 50: 888. [Crossref]

9. Turabian JL, Perez Franco B (2008) Atención médica individual con orientación comunitaria-Atención contextualizada: la figura es el fondo. Revista Clínica Electrónica en Atención Primaria.

10. Clayman ML, Morris MA (2013) Patients in context: recognizing the companion as part of a patient-centered team. Patient Educ Couns 91: 1-2. [Crossref]

11. Cené CW, Haymore LB, Lin FC, et al. (2015) Family member accompaniment to routine medical visits is associated with better self-care in heart failure patients. Chronic Illness 11: 21-32.

12. Andrades M, Kausar S, Ambreen A (2013) Role and Influence of the Patient's Companion in Family Medicine Consultations: "The Patient's Perspective". J Family Med Prim Care 2: 283-287. [Crossref]

13. Brown JB, Brett P, Stewart M, Marshall JN (1998) Roles and influence of people who accompany patients on visits to the doctor. Can Fam Physician 44: 1644-1650. [Crossref]

14. Adelman RD, Greene MG, Charon R (1987) The physician-elderly patient-companion triad in the medical encounter: the development of a conceptual framework and research agenda. Gerontologist 27: 729-734. [Crossref]

15. Ishikawa H, Roter DL, Yamazaki Y, Takayama T (2005) Physician-elderly patientcompanion communication and roles of companions in Japanese geriatric encounters. Soc Sci Med 60: 2307-2320. [Crossref]

16. Open Source Epidemiologic Statistics for Public Health.

17. Strauss AL (1984) Chronic illness and the quality of life. St Louis: The C.V. Mosby Company.

18. WHO (2016) International Classification of Diseases (ICD). ICD-10 ONLINE.

19. WHO (2016) Collaborating Centre for Drug Statistics Methodology. ATC/DDD Index.

20. Watts C, Shrader E (1998) How to do (or not to do) The genogram: a new research too to document patterns of decision-making, conflict and vulnerability within households. Health Policy and Planning; 13: 459-464.

21. De la Revilla Ahumada L (2015) El genograma en la practica clinica

22. Báez Montiel B, Turabián Fernández JL (2012) Un genograma "Ufff y Mmmm”. AMF Joven; $1: 3$.

23. McIlvain H, Crabtree B, Medder J, Stange KC, Miller WL (1998) Using practice genograms to understand and describe practice configurations. Fam Med 30: 490-496. [Crossref]

24. Royal Collage of General Practitioners ed. (1986) The Classification and Analisis of General Practice Data. Ocasional Paper 26.

25. Donaldson RJ, Donaldson LJ (1983) Essential Comunity Medicine. Lancaster: MTP Press.

26. Borrell F (1989) Manual de entrevista clínica. Barcelona: Doyma.

27. Castillo Barrera J, Schwartz Calero P, Pardo Álvarez J, Ortega Carpio A, Aguilar Valadez C, Pedregal González M (2003) El acompañante en la entrevista clínica: frecuencia y técnicas utilizadas. Medicina de Familia (And) 4: 136-138.

28. Statistical Package for the Social Sciences (SPSS) software.

29. Chen CY, Chen YJ, Juang YY, Liu CY, Hung CI (2004) Role and attitude of companion on geriatric psychiatry outpatient visits in Taiwan. Psychiatry Clin Neurosci 58: 257 261. [Crossref]

30. Rodríguez-González AM, Ramírez-Aranda JM, Santacruz-Belmonte MA, HernándezNieto M, Méndez-Espinoza E, Tamez-Tijerina MG (2011) Percepción médica sobre la influencia del acompañante en la consulta del primer nivel de atención. Medicina Universitaria; 13: 73-78.

31. de la Revilla L, Montoro R, Prados MA, Marcos B, Bailón E, et al. (1993) [The companion at the clinical interview]. Aten Primaria 11: 225-227. [Crossref]

32. Turabian JL, Minier-Rodriguez LE, Cucho-Jove R, Rodriguez-Almonte FE, VillarinCastro A (2016) The Patient Companion in the Consultation of Family Medical Practice is an Indicator of Hidden Family Problems. Scientific Pages Fam Med 1: 001.

33. Lang F, Marvel K, Sanders D, Waxman D, Beine KL, et al. (2002) Interviewing when family members are present. Am Fam Physician 65: 1351-1354. [Crossref]

34. Nitzan U, E Hirsch, Walter G, Lurie I, Aviram S Bloch Y (2012 ) Comprehension and companionship in the emergency department as predictors of treatment adherence Australas Psychiatry; 20: 112-116.

35. Turabian JL, Perez-Franco B (2016) The Companion of the Patient in the Family Doctor's Office: Making Visible The "Guardian Angel". J Community Med Health Educ 6: 453.

Copyright: (C2016 Turabian JL. This is an open-access article distributed under the terms of the Creative Commons Attribution License, which permits unrestricted use, distribution, and reproduction in any medium, provided the original author and source are credited. 